\title{
Thermal-plume fibre optic tracking (T-POT) test for flow velocity measurement in groundwater boreholes
}

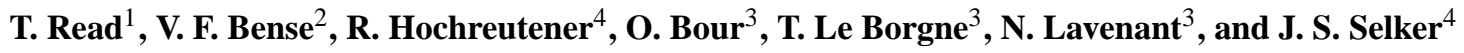 \\ ${ }^{1}$ School of Environmental Sciences, University of East Anglia, Norwich Research Park, Norwich, NR4 7TJ, UK \\ ${ }^{2}$ Hydrology and Quantitative Water Management Group, Department of Environmental Sciences, Wageningen University, \\ 6700 AA Wageningen, the Netherlands \\ ${ }^{3}$ Géosciences Rennes, UMR6118 - CNRS, University of Rennes 1, Rennes, France \\ ${ }^{4}$ Biological and Ecological Engineering, Oregon State University, Corvallis, OR 97331, USA \\ Correspondence to: T. Read (tom.read@uea.ac.uk)
}

Received: 23 April 2015 - Published in Geosci. Instrum. Method. Data Syst. Discuss.: 11 June 2015

Revised: 24 September 2015 - Accepted: 7 October 2015 - Published: 28 October 2015

\begin{abstract}
We develop an approach for measuring in-well fluid velocities using point electrical heating combined with spatially and temporally continuous temperature monitoring using distributed temperature sensing (DTS). The method uses a point heater to warm a discrete volume of water. The rate of advection of this plume, once the heating is stopped, equates to the average flow velocity in the well. We conducted thermal-plume fibre optic tracking (T-POT) tests in a borehole in a fractured rock aquifer with the heater at the same depth and multiple pumping rates. Tracking of the thermal plume peak allowed the spatially varying velocity to be estimated up to $50 \mathrm{~m}$ downstream from the heating point, depending on the pumping rate. The T-POT technique can be used to estimate the velocity throughout long intervals provided that thermal dilution due to inflows, dispersion, or cooling by conduction does not render the thermal pulse unresolvable with DTS. A complete flow log may be obtained by deploying the heater at multiple depths, or with multiple point heaters.
\end{abstract}

\section{Introduction}

The measurement of the vertical flow in wells can improve our conceptual understanding of subsurface fluid movement, which can aid in, for example, groundwater resource management or geothermal resource assessments. In open or long-screened wells penetrating multiple permeable units or fractures, vertical flow typically occurs under hydraulically unstressed conditions due to the natural occurrence of a vertical head gradient. Flow logs obtained under unstressed conditions give a qualitative guide to fracture inflow and outflow zones (Hess, 1986). Alternatively, flow logs obtained in a pumping well at multiple different pumping rates allow the depth variability of transmissivity to be estimated (Paillet et al., 1987). Flow logs in observation wells affected by nearby pumping enable the connectivity of fractures to be determined (Paillet, 1998; Klepikova et al., 2013). In all cases, the in-well flow is not directly indicative of flow in the formation itself, since the presence of the well as a high permeability vertical conduit allows the short-circuiting of flow. In addition, flow logs have inherent value for geochemical sampling campaigns. Ambient vertical flow through the well may redistribute contaminants and mean that passive sampling approaches do not reproduce the same depth variability as present in the aquifer itself (Elci et al., 2003). Typical flow logging techniques involve lowering an impeller or electromagnetic flowmeter down a well and either measuring continuously (trolling) or at multiple points with the probe held stationary. At low flows a heat pulse flowmeter may be used at fixed depths (Paillet, 1998).

Alternatively, tracer-based approaches may be used. Most commonly, a tracer is emplaced over the entire length of the borehole and the change in concentration monitored over time. Typically, slightly saline (Maurice et al., 2011) or distilled water (Doughty et al., 2005) is added since fluid electrical conductivity (EC) can be easily logged with an EC meter. The EC is then monitored over depth and time by making re- 
peated logs. The dilution of the saline profile at inflow locations or increase in EC if using distilled water can be used to estimate horizontal flow through the aquifer using simple analytical solutions (Pitrak et al., 2007). If there is vertical flow in the well, a salinity front then migrates up or down the well. In the case of multiple inflows with multiple salinity fronts, the response over depth and time may become complex and require numerical modelling (Maurice et al., 2011) or inversion methods to extract the vertical flow profile (Moir et al., 2014). A limitation of this method is that when the vertical velocity or losses from the borehole to the aquifer are high, the EC signal rapidly dissipates, and monitoring this process over a large depth interval with a single EC logger yields an incomplete data set. Additionally, density-induced flow effects in well bores are significant even for small gradients of fluid density (Berthold, 2010).

Instead of a hydrochemical signal that can be difficult to monitor over space and time, Leaf et al. (2012) introduced a slug of warm water to a target depth. By using temperature as the tracer, it is possible to monitor the response continuously over depth and time along a fibre optic cable installed in the well with the distributed temperature sensing (DTS) technique (see Selker et al. (2006) for a description of the DTS method). Leaf et al. (2012) heated water at the surface and injected it at multiple depths to identify the flow direction and velocity. However, the process of heating water is cumbersome, and its injection is likely to result in head changes in the well, resulting in an altered flow regime particularly if ambient or low pumping rate conditions are of interest. Sellwood et al. (2015) adapted this method by using an electrical heater to generate the thermal disturbance and carried out tests under non-hydraulically stressed conditions in a dual permeability sandstone aquifer. In this study we deploy a single electrical heater to warm a discrete interval of water at depth in a pumping well in a fractured rock aquifer, monitored with DTS. We apply post-collection averaging to the DTS temperature data and track the peak of the plume over time to estimate the mean vertical velocity. We call this method thermal-plume fibre optic tracking (T-POT).

\section{T-POT field application}

We employed T-POT at the $\mathrm{H}+$ network research site (hplus.ore.fr/en), Ploemeur, France (Fig. 1a). The site has multiple boreholes up to $100 \mathrm{~m}$ deep, penetrating mica-schist and granitic rock. Open fractures, although sparse (fewer than five hydrogeologically significant fractures per borehole), are reasonably transmissive (up to $\left.4 \times 10^{-3} \mathrm{~m}^{2} \mathrm{day}^{-1}\right)$. We show T-POT results from borehole B3 $(11.8 \mathrm{~cm}$ diameter), which is intersected by three previously identified transmissive fractures (Fig. 1b). Fractures B3-2 and B3-3 have similar transmissivities $\left(\sim 2 \times 10^{-3} \mathrm{~m}^{2} \mathrm{day}^{-1}\right)$, while B3-1 is approximately an order of magnitude less transmissive (Klepikova, 2013).

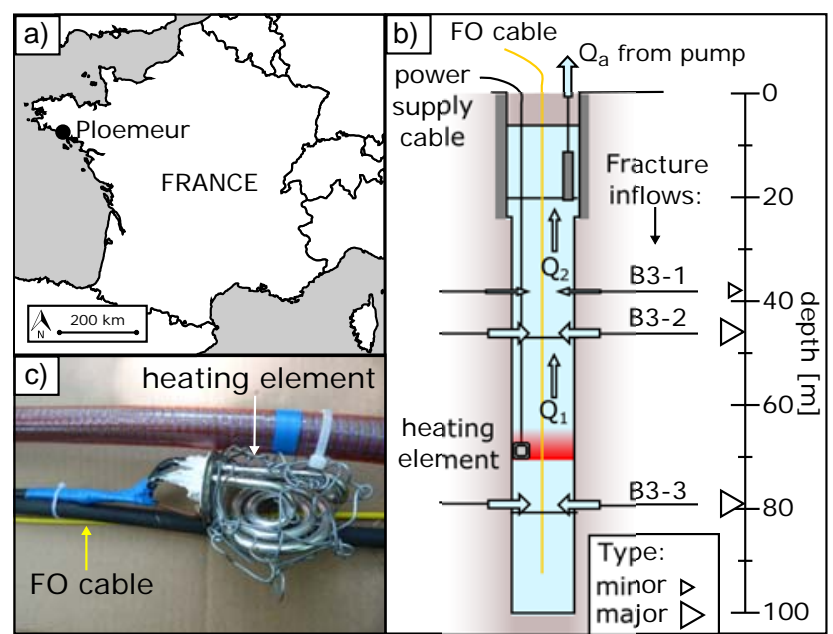

Figure 1. (a) Location of the Ploemeur research site; (b) heating element and fibre optic cable along which temperature is measured; (c) schematic of the set-up in borehole B3 at the site.

We used a $2 \mathrm{~kW}$ rated heating element as the heat source (Fig. 1c), lowered down to $68 \mathrm{~m}$ depth for the duration of the experiment. Additionally, an armoured fibre optic cable was installed in the well down to a depth of approximately $80 \mathrm{~m}$. This allowed temperature measurements to be made over a time average of $5 \mathrm{~s}$ and a sampling interval of $0.12 \mathrm{~m}$ with DTS by connecting it to a Silixa ULTIMA base unit. The cable was configured for a duplexed single-ended measurement. The DTS data were calibrated using three reference sections from a cold and ambient bath, according to the method described by Hausner et al. (2011). The standard deviation of temperature in the cold and ambient baths for the $5 \mathrm{~s}$ integration time averaged 0.38 and $0.33^{\circ} \mathrm{C}$ respectively over the duration of the T-POT tests.

We ran a series of tests at different pumping rates to determine the fracture inflow for each pumping rate, in order to evaluate the T-POT method. For each pumping rate, a similar procedure was followed: heat for $\sim 10 \mathrm{~min}$, then switch off the heating and simultaneously turn on the pump at the selected rate. We repeated this procedure for pumping rates of 7.3, 40.0, 86.6, 104.0, and 136.2 $\mathrm{L} \mathrm{min}^{-1}$. During each experiment we measured the pumping rate manually and with an in-line flowmeter, drawdown, electrical power supplied to the heating element, and temperature along the length of the borehole with DTS.

\section{T-POT results and interpretation}

Figure 2 shows successive DTS temperature-depth profiles from the five T-POT experiments. A background temperature-depth profile, defined by a $1 \mathrm{~min}$ time average immediately prior to the start of heating, was subtracted from each data set. During the heating phase $(t<0 \mathrm{~min})$, it 
a)

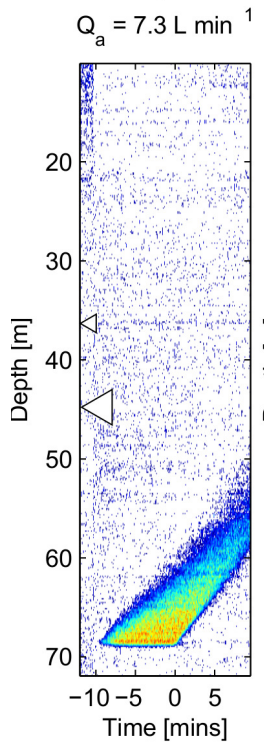

b)

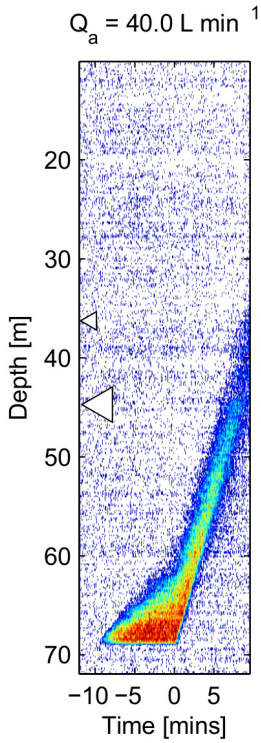

c)

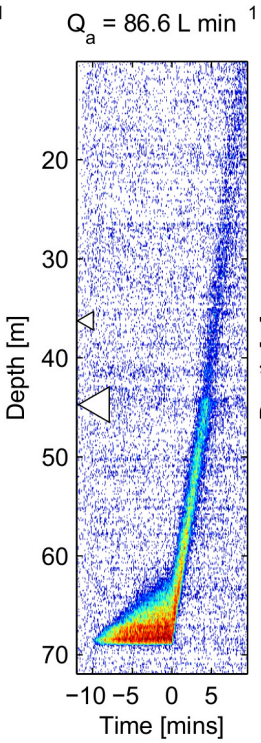

d)

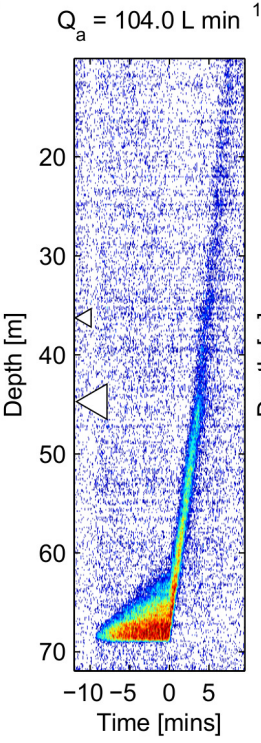

e)

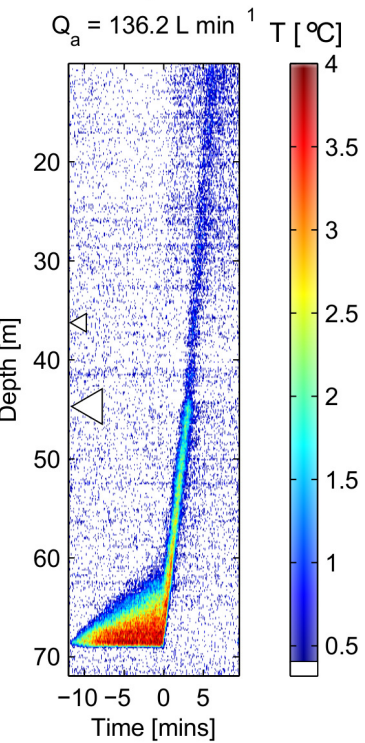

Figure 2. Temperature distribution with depth and time for T-POT tests at abstraction rates of (a) 7.3, (b) 40.0, (c) 86.6, (d) 104.0, and (e) $136.2 \mathrm{~L} \mathrm{~min}^{-1}$. The temperature data have a background profile subtracted, with the lower limit to the colour scale starting 1 standard deviation (from reference bath temperature measurements) above the $0^{\circ} \mathrm{C}$ change.

appears that the plume develops asymmetrically, with the base of the plume at $68 \mathrm{~m}$ at the approximate depth of the heater. The heater is switched off at $t=0$ and at this moment pumping is initiated. The plume is then advected upwards at higher velocity. In all cases, the linear path of the plume in the temperature-depth-time plot suggests a uniform velocity from $68 \mathrm{~m}$ to around $45 \mathrm{~m}$, as would be expected given the lack of transmissive fractures and uniform borehole diameter in this interval. At $45 \mathrm{~m}$, the temperature signal is significantly reduced and the plume then continues to move upwards at higher velocity (steeper gradient in Fig. 2c-e). This coincides with a transmissive fracture identifiable in previous flowmeter tests and optical borehole logs (Le Borgne et al., 2007).

To aid the identification of the plume peak, the $5 \mathrm{~s}$ time averaged and $0.12 \mathrm{~m}$ spatially sampled DTS temperature data were then subsequently further averaged to give the equivalent of $15 \mathrm{~s}$ time-averaged DTS temperature data. Each point was then spatially smoothed with a nine-point moving average window. These are plotted as temperature-depth profiles in Fig. 3. Below $45 \mathrm{~m}$, the plume is clearly defined. Above the inflow from B3-2 at $45 \mathrm{~m}$, the plume becomes much less discernible (Fig. 3c-e).

The depth location of the maximum temperature was then extracted and plotted over time (Fig. 4). While the peak of the plume remains below fracture B3-2, the plume is readily resolvable in the temperature data. Linear least-squares regression yields an $r^{2} \geq 0.98$ for all of the pumping rates. The average flow velocities $v_{1}$ and $v_{2}$ were calculated from the gradient of the best fit line through plume peak location data.
The corresponding volumetric flow rates $Q_{\mathrm{B} 3-3}$ and $Q_{\mathrm{B} 3-1,2,3}$ were calculated from $v_{1}$ and $v_{2}$ respectively using the known borehole diameter over this interval.

Above $45 \mathrm{~m}$, the peak of the plume was not detected for $1-2$ min after the arrival of the plume peak at B3-2. This is because in this situation, the inflow from B3-2 greatly dilutes the thermal signal, such that until most of the plume has moved above the fracture, the highest temperature (and plume peak, as identified with this method) remains at the depth of the fracture. Once identified again, now at approximately the depth of B3-1, the peak location data show that the plume is now travelling at higher velocity. Here it is much less detectable, with an $r^{2}$ for the three cases where the plume passes this point of $0.76,0.65$, and 0.91 . However, it is not possible to separately assess the flow contributions of B3-2 and B3-1, since two separate contributions are not apparent in Figs. 2-4. Therefore we are only able to estimate $Q_{\mathrm{B} 3-3}$ (the flow below $45 \mathrm{~m}$ ) and $Q_{\mathrm{B} 3-1,2,3}$ representing the cumulative flow contribution from all transmissive fractures intersecting the well.

\section{Discussion}

The upwards expansion of the plume during the heating phase is driven by upward ambient fluid flow in the borehole. The rate of the ambient flow component between B33 and B3-2 has been measured at approximately $5 \mathrm{~L} \mathrm{~min}^{-1}$ in previous studies (Klepikova, 2013). When pumping at 7.3 $\mathrm{L} \mathrm{min}^{-1}$, the calculated flow between B3-3 and B3-2, $Q_{\mathrm{B} 3-3}$, is almost double the abstraction rate. At this low 
a)

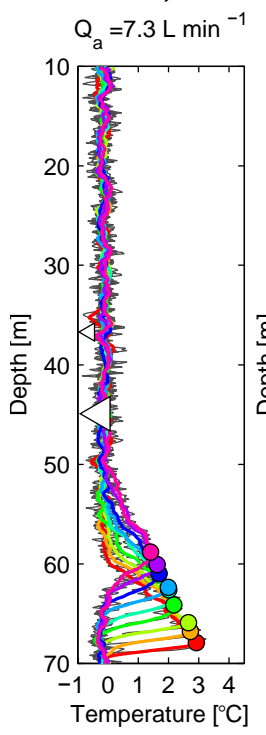

b)

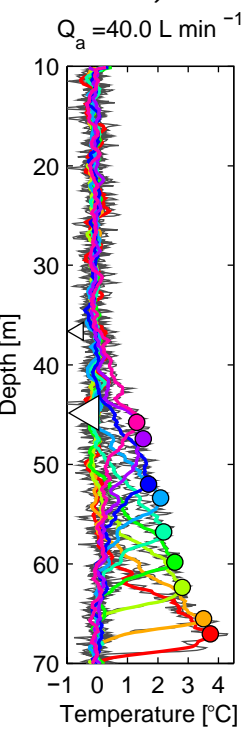

c)

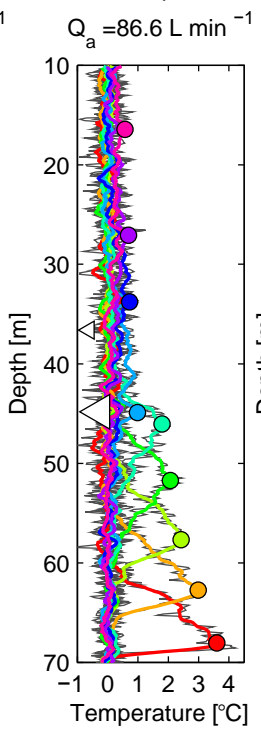

d)

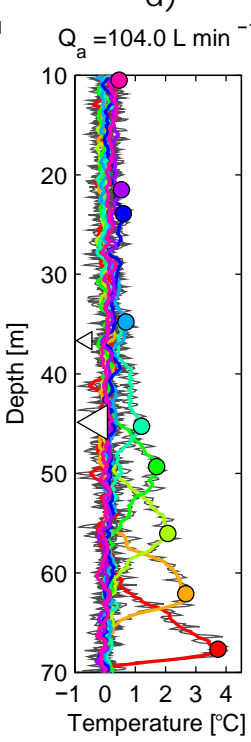

e)

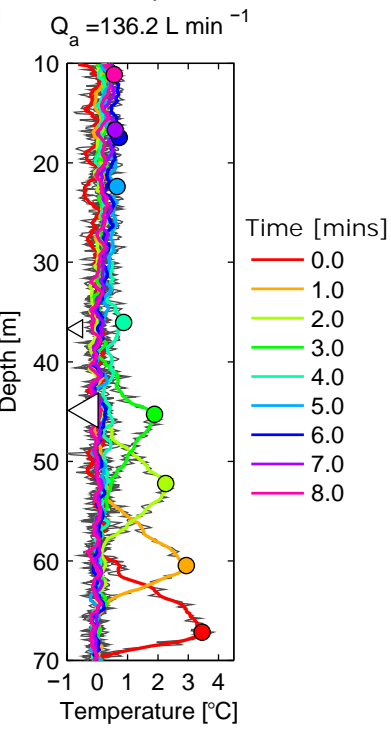

Figure 3. Temperature-depth profiles after pumping begins for the T-POT tests at abstraction rates of (a) 7.3, (b) 40.0, (c) 86.6, (d) 104.0, and (e) $136.2 \mathrm{~L} \mathrm{~min}^{-1}$. The coloured profiles are $15 \mathrm{~s}$ time-averaged data that have then been spatially smoothed with a nine-point moving window. Filled circles identify the locations of the plume peaks.

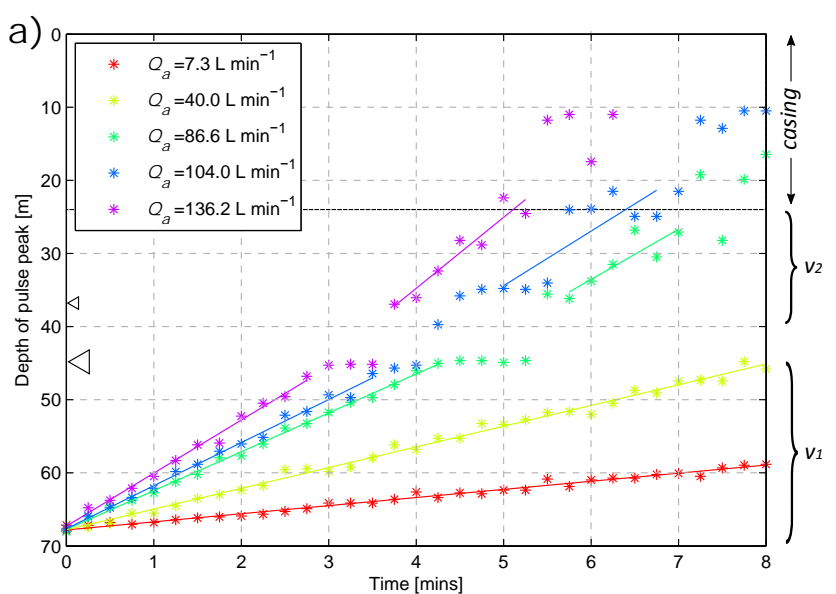

b)

\begin{tabular}{|c|c|c|c|c|c|c|}
\hline $\begin{array}{l}v_{1} \\
{\left[\mathrm{~cm} \mathrm{~s}^{-1}\right]}\end{array}$ & $\begin{array}{c}v_{2} \\
{\left[\mathrm{~cm} \mathrm{~s}^{-1}\right]}\end{array}$ & $r^{2}\left(v_{1}\right)$ & $r^{2}\left(v_{2}\right)$ & $\begin{array}{c}Q_{B 3-3} \\
{\left[\mathrm{~L} \mathrm{~min}^{-1}\right]}\end{array}$ & $\begin{array}{r}Q_{B 3-1,2,3} \\
{\left[\mathrm{~L} \mathrm{~min}^{-1}\right]}\end{array}$ & $\begin{array}{c}Q_{a} \\
{\left[\mathrm{~L} \mathrm{~min}^{-1}\right]}\end{array}$ \\
\hline 1.85 & - & 0.99 & - & 12.12 & - & 7.3 \\
\hline 4.73 & - & 0.99 & - & 31.01 & $\begin{array}{ll}- & \text { r }\end{array}$ & 40 \\
\hline 8.86 & 11.45 & 1.00 & 0.76 & 58.12 & 75.10 & 86.6 \\
\hline 9.82 & 12.44 & 0.99 & 0.65 & 64.40 & 81.61 & 104 \\
\hline * 12.09 & 16.20 & 0.99 & 0.91 & 79.34 & 106.32 & 136.2 \\
\hline
\end{tabular}

Figure 4. Temperature peak depth over time for each of the pumping rates, with linear least-squares regression best fit lines used to estimate the in-well vertical flow velocity.

pumping rate, the hydraulic head in the borehole remains higher than the hydraulic head in B3-1, so that B3-1 remains an outflow. The flow from B3-3 is proportional to the pump- ing rate $\left(r^{2}=0.99\right)$, as would be expected from linear scaling behaviour, giving us confidence in these flow estimates. The discrepancy between $Q_{\mathrm{B} 3-1,2,3}$ and $Q_{\mathrm{a}}$ is at most $20 \%$. Much of this error may arise from the error determining the plume location above B3-1. Further additional sources of error that may contribute to the discrepancy in flow estimates are the high sensitivity of the volumetric flow estimate to the borehole diameter used for the calculation, and error in independently measuring the flow at the surface. The inability of the method to reliably track the velocity immediately downstream of fracture B3-2 in the present study is due to the strong dilution effect by inflow from the fracture of a similar magnitude to the vertical flow in the borehole. The relatively low $r^{2}$ for the peak depth-time data beyond this fracture and the discrepancy from $Q_{\mathrm{a}}$ is because the resulting plume is much more dispersed with a poorly defined peak. The T-POT method as used here would more likely perform better in cases where there are multiple outflows, rather than inflows. This is because inflows both affect the size and change the shape of the signal.

Free convection due to T-POT heating-induced buoyancy, as occurs naturally in groundwater wells even for small temperature gradients (Sammel, 1968), may disturb the in-well flow. The potential for heat transfer by natural convection in a fluid is expressed by the Rayleigh number, given by

$R a=\frac{\beta g \Delta T / \Delta z}{\kappa \nu} r^{4}$,

where $\beta$ is the thermal expansion coefficient, $g$ is acceleration due to Earth's gravity, $\Delta T / \Delta z$ the temperature gradient, $\kappa$ the thermal diffusivity, $v$ kinematic viscosity, and 
$r$ the characteristic length, which in this case is the borehole radius. For the T-POT experiments here in a borehole with radius $0.059 \mathrm{~m}$, with $\Delta T / \Delta z$ at most $0.5^{\circ} \mathrm{C} \mathrm{m}^{-1}$ during the heating phase, substituting values of $2 \times 10^{-4}{ }^{\circ} \mathrm{C}^{-1}$, $9.81 \mathrm{~m} \mathrm{~s}^{-2}, 0.14 \times 10^{-6} \mathrm{~m}^{2} \mathrm{~s}^{-1}$, and $1 \times 10^{-6} \mathrm{~m}^{2} \mathrm{~s}^{-1}$ for $\beta$, $g, \kappa$, and $v$ respectively gives a $R a$ of 85000 . Scaling the results of Berthold and Resagk (2012), who imaged flow velocities due to free convection in a vertical cylinder, using this Rayleigh number, suggests that in the absence of any forced convection, free convection due to T-POT heating would give rise to flow velocities of the order of $2 \mathrm{~cm} \mathrm{~s}^{-1}$. This is similar to the velocity that would be expected under ambient flow conditions. However, this velocity is the velocity magnitude in a diametrically anti-symmetric convection cell. Therefore, even though the velocity due to natural convection is of a similar magnitude to the ambient flow, if the convection cells are relatively small, then the warming front would not propagate up the well at this rate. A further in-depth analysis is beyond the scope of this paper, but we note that if present, the development of large convection cells would place a lower limit on the velocity estimate that can be obtained with the T-POT method.

The upper limit of velocity estimation is reached when the plume travels the length of the monitoring interval in less than the integration time of the DTS temperature measurement (i.e. $v_{\max }=Z / t_{\mathrm{i}}$, where $Z$ is the length of the flow path away from the heater in the direction of flow, and $t_{\mathrm{i}}$ is the integration time of the DTS temperature measurement). The depth resolutions of the velocity estimate using the T-POT method are flow velocity dependent. At high velocities, the depth spacing between velocity estimates is $t_{\mathrm{i}} v$. At low flow velocities, the spatial sampling of the DTS instrument determines the number of velocity estimates with depth that the T-POT method can provide.

The basic method, using DTS with a fibre optic cable and point source electrical heating in the well, can easily be adapted to include the use of multiple heaters or more prolonged heating in a constant source type experiment. While the method at present assumes a constant velocity profile in time, time-varying velocities could be monitored by cycling through heating and non-heating phases. The method is completely complementary to and can easily be used alongside other fibre-optic down hole tests and to validate vertical velocity estimates made by other active DTS methods such as Read et al. (2014).

\section{Conclusions}

We employed the T-POT method in a groundwater well in fractured rock. By heating a discrete volume of the resident water in the borehole, estimates of vertical in-well velocity were obtained by tracking its subsequent migration with DTS. The plume was significantly reduced beyond a major inflowing fracture but was still detectable, albeit with much increased uncertainty. The advantage of this method is that it is quick and simple, especially if the well is already instrumented for fibre optic temperature monitoring.

Acknowledgements. Funding for this work was provided by INTERREG IV project CLIMAWAT, the national network of hydrogeological sites $\mathrm{H}+$, ANR project CRITEX ANR-11-EQPX0011, and a Natural Environment Research Council (NERC) studentship (NE/J500069/1) to Tom Read. Part of the support for the participation of John Selker and provision of some of the fibre optic cables were provided by the Center for Transformative Environmental Monitoring Programs (CTEMPs) funded by the National Science Foundation. The data collected for this study will be available from the national network of hydrogeological sites $\mathrm{H}+$ at http://hplus.ore.fr/en/.

Edited by: A. Benedetto

\section{References}

Berthold, S.: Synthetic Convection Log - Characterization of vertical transport processes in fluid-filled boreholes, J. Appl. Geophys., 72, 20-27, doi:10.1016/j.jappgeo.2010.06.007, 2010.

Berthold, S. and Resagk, C.: Investigation of thermal convection in water columns using particle image velocimetry, Exp. Fluids, 52, 1465-1474, doi:10.1007/s00348-012-1267-7, 2012.

Doughty, C., Takeuchi, S., Amano, K., Shimo, M., and Tsang, C.-F.: Application of multirate flowing fluid electric conductivity logging method to well DH-2, Tono Site, Japan, Water Resour. Res., 41, W10401, doi:10.1029/2004WR003708, 2005.

Elci, A., Flach, G. P., and Molz, F. J.: Detrimental effects of natural vertical head gradients on chemical and water level measurements in observation wells: identification and control, J. Hydrol., 281, 70-81, doi:10.1016/S0022-1694(03)00201-4, 2003.

Hausner, M. B., Suárez, F., Glander, K. E., Giesen, N. V. D., Selker, J. S., and Tyler, S. W.: Calibrating Single-Ended Fiber-Optic Raman Spectra Distributed Temperature Sensing Data, Sensors, 11, 10859-10879, doi:10.3390/s111110859, 2011.

Hess, A. E.: Identifying hydraulically conductive fractures with a slow-velocity borehole flowmeter, Can. Geotech. J., 23, 69-78, 1986.

Klepikova, M. V.: Imaging of fractured rock properties from flow and heat transport: field experiments and inverse modelling, PhD thesis, Geosciences Rennes, Rennes, 2013.

Klepikova, M. V., Le Borgne., T., Bour, O., and de Dreuzy, J.-R.: Inverse modeling of flow tomography experiments in fractured media, Water Resour. Res., 49, 7255-7265, doi:10.1002/2013WR013722, 2013.

Leaf, A. T., Hart, D. J., and Bahr, J. M.: Active Thermal Tracer Tests for Improved Hydrostratigraphic Characterization, Ground Water, 50, 726-735, doi:10.1111/j.1745-6584.2012.00913.x, 2012.

Le Borgne, T., Bour, O., Riley, M., Gouze, P., Pezard, P., Belghoul, A., Lods, G., Le Provost, R., Greswell, R., Ellis, P., Isakov, E., and Last, B.: Comparison of alternative methodologies for identifying and characterizing preferential flow paths in heterogeneous aquifers, J. Hydrol., 345, 134-148, doi:10.1016/j.jhydrol.2007.07.007, 2007. 
Maurice, L., Barker, J., Atkinson, T., Williams, A., and Smart, P.: A Tracer Methodology for Identifying Ambient Flows in Boreholes, Ground Water, 49, 227-238, doi:10.1111/j.17456584.2010.00708.x, 2011.

Moir, R. S., Parker, A. H., and Bown, R. T.: A simple inverse method for the interpretation of pumped flowing fluid electrical conductivity logs, Water Resour. Res., 50, 6466-6478, doi:10.1002/2013WR013871, 2014.

Paillet, F. L.: Flow modeling and permeability estimation using borehole flow logs in heterogeneous fractured formations, Water Resour. Res., 34, 997-1010, doi:10.1029/98WR00268, 1998.

Paillet, F. L., Hess, A. E., Cheng, C. H., and Hardin, E.: Characterization of Fracture Permeability with High-Resolution Vertical Flow Measurements During Borehole Pumping, Ground Water, 25, 28-40, doi:10.1111/j.1745-6584.1987.tb02113.x, 1987.

Pitrak, M., Mares, S., and Kobr, M.: A Simple Borehole Dilution Technique in Measuring Horizontal Ground Water Flow, Ground Water, 45, 89-92, doi:10.1111/j.1745-6584.2006.00258.x, 2007.
Read, T., Bour, O., Selker, J. S., Bense, V. F., Borgne, T. L., Hochreutener, R., and Lavenant, N.: Active-distributed temperature sensing to continuously quantify vertical flow in boreholes, Water Resour. Res., 50, 3706-3713, doi:10.1002/2014WR015273, 2014.

Sammel, E. A.: Convective flow and its effect on temperature logging in small diameter wells, Geophysics, 33, 1004-1012, doi:10.1190/1.1439977, 1968.

Selker, J. S., Thévenaz, L., Huwald, H., Mallet, A., Luxemburg, W., Van De Giesen, N., Stejskal, M., Zeman, J., Westhoff, M., and Parlange, M. B.: Distributed fiber-optic temperature sensing for hydrologic systems, Water Resour. Res., 42, W12202, doi:10.1029/2006WR005326, 2006.

Sellwood, S., Hart, D., and Bahr, J.: An in-well heat-tracer-test method for evaluating borehole flow conditions, Hydrogeol. J., doi:10.1007/s10040-015-1304-8, in press, 2015. 